\title{
Nutrient Intake, Physical Activity and Nutritional Status Among Second Cycle Students in Tamale, Ghana
}

\author{
P. P. M. Dapare ${ }^{1}$, Y. Adams ${ }^{1}$, E. K. Djabuni², I. Osei², S. O. Shittu ${ }^{3}$ \\ ${ }^{1}$ Department of Biomedical Laboratory Science, ${ }^{2}$ Department of Community Nutrition, ${ }^{3}$ Department of Nursing, School of Allied Health \\ Sciences, University for Development Studies, Tamale, Ghana
}

\begin{abstract}
The issues of nutrition and dietary habits are timely because nutrition plays an important role among the external factors that may impact the health of an individual. The main objective of this study was to assess the impact of nutrient intake and physical activity on nutritional status of second cycle students within the Tamale Metropolis, Ghana. This descriptive cross sectional study was conducted from February, 2015 to April, 2015 where a total of 200 students, comprising both male (49.5\%) and female (50.5\%) students were conveniently selected from two schools; a day school (44\%) and a boarding school (56\%). A questionnaire containing closed ended and open ended questions were developed to cover socio-demographic characteristics, anthropometric measures, physical activity and nutrients intake. The mean age of the participants was $17.78 \pm 1.7$ years. The prevalence of overweight and obesity in this study were $6 \%(\mathrm{BMI}), 28 \%$ (WHR) and $1 \%(\mathrm{BMI}), 10 \%$ (WHR) respectively. The prevalence of underweight and high physical activity was higher in males ( $\mathrm{p}=0.0017$ and $\mathrm{p}=0.0027$ respectively) whiles the prevalence of overweight, obesity and low physical activity were higher in females $(\mathrm{p}=<0.0001, \mathrm{p}=0.0023$ and $\mathrm{p}=<0.0001$ respectively). The mean total daily energy intake of the study population was $4177 \pm 7569 \mathrm{Kcal} /$ day. Males significantly consumed more calories $(p=0.0189)$, carbohydrates $(p=0.0401)$, proteins $(p=0.0282)$ and iron $(p=0.035)$ than females. Prevalence of overweight and high physical activity were higher in day students $(\mathrm{p}=<0.0001$ and $\mathrm{p}=0.0014$ respectively) whiles prevalence of overweight and low physical activity were found in boarding students $(\mathrm{p}=0.0257$ and $\mathrm{p}=<0.0001$ ). This study brings to bare the increasing prevalence of underweight, overweight and obesity in adolescents, hence the dual burden of under nutrition and over nutrition. It brings to light the higher prevalence of overweight and obesity among female adolescents as a consequence of reduced physical activity. The study also reveals the nutritional deficiencies coupled with reduced physical activity in boarding school students as well as the unhealthy eating habits of day school students.
\end{abstract}

Journal of Medical and Biomedical Sciences (2017) 6(2), 25- 37

Keywords: Obesity, Physical activity, undernutrition, over nutrition, Tamale

\section{INTRODUCTION}

The issues of nutrition and dietary habits are timely because nutrition plays an important role among the external factors that may impact the health of an individual (Deshmukh et al., 2006). A special situation arises in adolescence due to greater physiological need for food of high nutritional value (WHO, 2006a) and due to the start of behaviours that may become life-time habits that result in diseases many years later (WHO, 1995). Several studies from

Correspondence: P. P. M. Dapare, Department of Biomedical Laboratory Science, School of Allied Health Sciences, University for Development Studies, Tamale.

E-mail: peterpauldapare@yahoo.com around the world have shown that there is a high probability that adolescents who develop good eating habits in adolescence and keep them into adulthood, will have a lower risk of chronic diseases that are, in some degree, related to food intake (e.g. Obesity, Diabetes mellitus and hypertension) (Deckelbaum and Williams, 2001; Guo et al., 2002; Sharma et al., 2008).

There is an increasing frequency of imbalance in the nutritional state of adolescents which manifests itself in eating disorders resulting in overweight/ obesity and underweight (Popkin, 2002). Obesity is a medical condition in which excess body fat has accumulated to the extent that, it may have an ad- 


\section{Nutritional status among Senior High Students}

Dapare et al.,

verse effect on health leading to reduced life expectancy and or increased health problems (WHO, 2006b). The main cause of obesity is the discrepancy between the intake of food and the output of energy. Also rising is the number of adolescents who are underweight because of insufficient nutrition, inappropriate dieting, and eating disorders (Daniels et al., 2005). A decreasing trend in the prevalence of under -nutrition/underweight has been identified in developing countries whiles some countries face a dual burden of under nutrition and over nutrition. However, in recent times, an increasing shift towards higher rates of overweight and obesity among adolescents has been reported in developed and developing countries and has already reached epidemic proportions (Popkin et al., 2001; Popkin, 2002; LobCorzilius, 2007).

Physical activity declines with age, falling off from adolescence, and is associated with overweight/ obesity and other chronic diseases (WHO, 2006b). Available survey data indicate that less than 1 in every 4 adolescents meets the recommended guidelines for physical activity of 60 minutes of moderate to vigorous physical activity daily (Fakhouri et al., 2014). Diet and physical activity influence health both together and separately. Although the effects of diet and physical activity on health often interact, particularly in relation to obesity, there are additional health benefits to be gained from physical activity that are independent of nutrition and diet, and there are significant nutritional risks that are unrelated to obesity (WHO, 2006b).

High school students (mostly adolescents) are potentially important targets for the promotion of healthy lifestyles as this may reduce the risks of lifestylerelated disorders later in life. They have been considered to have the lowest mortality among different age groups and have therefore received low priority in terms of nutritional status assessment as compared to younger children and adults (Woodruff and Duffield, 2000). However, because of the rapid growth in stature, muscle and fat mass during the peak of the adolescent growth spurt, the requirements for some nutrients is higher in adolescents than in any other age groups (WHO, 2000). Entering into the high school marks the first step towards independence from parental control for many adolescents. Outside the family home, most high school students make their own food choices and may exhibit unhealthy eating behaviours due to high cost of healthy foods and the availability of fast foods and junk foods at cheaper prices (Gan $e t$ al., 2011). This unhealthy eating behaviour is usually significantly coupled with reduced physical activity as a result of proliferation of more indoor and less physically involving activities.

Although several studies from around the world have reported significant decline in proper dietary behaviour and the level of physical activity among adolescents and its impact on their nutritional status (Popkin, 2002; Fakhouri et al., 2014), very few studies have been conducted in Ghana. This study therefore seeks to determine the impact of nutrient intake and physical activity on the nutritional status of high school students in the Tamale metropolis.

\section{MATERIALS AND METHODS \\ Study Area and Design}

This study is a descriptive cross sectional study on the impact of nutrient intake and physical activity on nutritional status of second cycle students that was conducted from February, 2015 to April, 2015 in the Tamale metropolis, Ghana.

\section{Study Population}

The target population of this study was students across various academic levels and courses from two selected senior high schools, a day and a boarding school, in the Tamale metropolis.

\section{Sample Size}

The necessary minimum sample size for the study is calculated to be 159 students, based on the assumption that $11.7 \%$ of adolescents are overweight/obese (Nyawornota et al., 2013), with an expected difference of $5 \%$ between the sample and the general population and a type I error $(\alpha)$ of 0.05 .

$$
n=\frac{z^{2}(1-p) p}{d^{2}}
$$

Where $\mathrm{n}=$ minimum sample size; $\mathrm{Z}=$ standard 
Nutritional status among Senior High Students Dapare et al.,

normal variance $=1.96$ to obtain a power of $95 \%$ confidence interval $(\beta=5 \%)$ and a type 1 error probability of $5 \% ; \mathrm{d}=$ Absolute standard error $=0.05$; $\mathrm{p}=$ prevalence $=11.7 \%$. The sample size was recalculated to eliminate any possible loss of precision. Given a targeted response rate of $90 \%$, the sample size was recalculated as: 159/0.90. Using the above formula, the calculated sample size was approximately 176. Two hundred (200) students were therefore recruited.

\section{Sampling Technique}

A purposive sampling technique was used to select the schools whiles a convenient sampling technique was employed in selecting the participants for this study.

\section{Data Collection}

A questionnaire containing closed ended and open ended questions were developed. The questionnaire was developed to cover four (4) sections. Section A: sociodemographic characteristics; section B: anthropometric measures; section C: physical activity and duration and section D: Nutrient Intake.

\section{Sociodemographic}

A self-designed questionnaire was administered to each consented study subject for sociodemographic information including age, gender, name of school, residential status, course of study, course level and behavioural activities (smoking and alcohol consumption). Alcohol intake was defined as the intake of at least one bottle of an alcoholic beverage per week and smoking was defined as smoking at least one cigarette a day.

\section{Anthropometry}

Respective weights and heights, waist and hip circumferences of each subject were measured to assess their nutritional status. The height and weight were taken using a microtoise and an electronic scale respectively and a measuring tape was used to measure both the waist circumference and hip circumference of each participant. The waist measurement was made midway between the inferior angle of the ribs and the suprailiac crest and hip measurements were done at the maximal circumference over the but- tocks.

\section{Nutrient Intake}

The students were asked to recall and describe carefully all foods (including beverages) that have been taken in the last 24 hours period. Details as regards to the type of food and the amount consumed were recorded. Data obtained from 24 hours dietary recall questionnaire was analysed using the local food composition table of the National Nutritional Institute and the NutriBase 7 software clinical edition to obtain the mean daily intake of energy, macronutrients and some micronutrients.

\section{Physical Activity}

Physical activity level was assessed using a questionnaire through an interview. A short IPAQ questionnaire which contains details on physical activity habits such as type, duration, and frequency of PA participation. The types of PA were categorized into three intensity levels and assigned metabolic equivalent values (MET) according to the compendium of PA. One MET equals the energy expenditure at rest, or roughly $3.5 \mathrm{ml}$ of oxygen consumed per $\mathrm{kg}$ of body weight per minute. The types of PA categories included the following; vigorous intensity activities like heavy lifting, digging, aerobics, or fast bicycling (MET =7), moderate physical activities like carrying light loads, bicycling at a regular pace, or doubles tennis $(\mathrm{MET}=6)$, and mild intensity activities such as walking $(\mathrm{MET}=2.5)$. The vigorous and moderate PA intensity were based on at least 10 minutes of physical activity.

\section{Statistical Analysis}

Data was analysed using Microsoft Excel 2010 and GraphPad Prism Version 6.0. Means and standard deviations were determined for relevant variables. Comparison of categorical variables was done using the chi-square test whiles continuous variables were compared using the unpaired t-test. In all cases, a $\mathrm{p}$ value $<0.05$ was seen as significant.

\section{RESULTS}

\section{General characteristics of study population}

Two hundred (200) students from two (2) schools were selected to participate in this study. A total of 


\section{Nutritional status among Senior High Students}

Dapare et al.,

$112(56 \%)$ students were from a boarding school and $88(44 \%)$ from a day school. Of the total number, 101 were males and 99 were females representing $50.5 \%$ and $49.5 \%$ respectively. The mean age of the participants was $17.78 \pm 1.70$ years. The mean age of the males $(18.39 \pm 1.79 ; \mathrm{p}=<0.0001)$ was significantly higher than that of the females (17.15 \pm 1.35$)$. Again, the males were heavier and taller than $\mathrm{Fe}$ males with $\mathrm{p}$-values of 0.0384 and $<0.0001$. The mean \pm SD for BMI $\left(\mathrm{kg} / \mathrm{m}^{2}\right)$,WC $(\mathrm{cm}), \mathrm{HC}(\mathrm{cm})$, WHR $(\mathrm{kg} / \mathrm{m})$, MET Score (mins/week) and Seden-

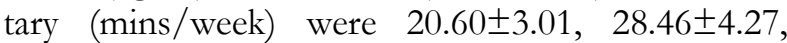
$34.10 \pm 2.74, \quad 0.84 \pm 0.11, \quad 1726 \pm 1831, \quad$ and $504.20 \pm 117.40$ respectively. In comparison, the mean WHR, MET Score were significantly higher in males (0.86 $\pm 0.14 ; \quad \mathrm{p}=0.0002$ and $2274 \pm 1973$; $\mathrm{p}=<0.0001$ for WHR and MET Score respectively) whiles BMI and $\mathrm{HC}$ were higher in females (21.34 $\pm 3.26 ; \mathrm{p}=0.0005$ and 35.27 $\pm 2.64 ; \mathrm{p}=<0.0001$ for BMI and $\mathrm{HC}$ respectively) (Table 1).

\section{Nutrient intake of studied population}

The mean \pm SD of the nutrients studied; Total calories, Carbohydrates, Proteins, Fats, Calcium, Phos- phorus, Iron, Vitamin A and Vitamin C were $4177 \pm 7569, \quad 628.1 \pm 1279, \quad 169.90 \pm 477.80$, $141.80 \pm 354.70, \quad 605 \pm 1417, \quad 1113 \pm 2954$, $49.11 \pm 155.00,289.60 \pm 1576$ and $33.42 \pm 168.00$ respectively. Males significantly consumed more calories $(\mathrm{p}=0.0189)$, carbohydrates $(\mathrm{p}=0.0401)$, proteins $(p=0.0282)$ and iron $(p=0.035)$ than females but there were no significant differences in males and females' intake of fats, calcium, phosphorus, vitamin $A$ and vitamin $C$ although intakes were higher among males than females (Table 2).

\section{Nutritional status and physical activity level}

Using BMI as the criterion for weight classification, $45(22.5 \%)$ of the students were Underweight, 141 $(70.5 \%)$ normal weight, $12(6 \%)$ overweight and 2 $(1 \%)$ obese. There was a significantly higher proportion of Underweight males $(31.68 \%$; $\mathrm{p}=0.0017)$ than females $(13.13 \%)$ whiles the proportions of normal weight, overweight and obese among males and females was not significant although the proportions were higher in females than males (Figure 1).

Table 1: Demographic and Anthropometric Characteristics of Study Subjects Stratified by Gender

\begin{tabular}{|c|c|c|c|c|}
\hline Variable & Total $(n=200)$ & Male $(n=101)$ & Female $(n=99)$ & p-value \\
\hline Age(years) & $17.78 \pm 1.70$ & $18.39 \pm 1.79$ & $17.15 \pm 1.35$ & $<0.0001$ \\
\hline \multicolumn{5}{|l|}{ Residential status } \\
\hline Boarding & $112(56 \%)$ & $53(52.48 \%)$ & $59(59.60 \%)$ & 0.3104 \\
\hline Day & $88(44 \%)$ & $48(47.52 \%)$ & $40(40.40 \%)$ & 0.3104 \\
\hline \multicolumn{5}{|l|}{ Anthropometry } \\
\hline Weight $(\mathrm{Kg})$ & $59.35 \pm 8.37$ & $60.56 \pm 8.57$ & $58.11 \pm 8.02$ & 0.0384 \\
\hline Height(m) & $1.70 \pm 0.10$ & $1.746 \pm 0.08$ & $1.65 \pm 0.01$ & $<0.0001$ \\
\hline $\operatorname{BMI}\left(\mathrm{kg} / \mathrm{m}^{2}\right)$ & $20.6 \pm 3.01$ & $19.88 \pm 2.55$ & $21.34 \pm 3.26$ & 0.0005 \\
\hline $\mathrm{WC}(\mathrm{cm})$ & $28.46 \pm 4.27$ & $28.44 \pm 5.52$ & $28.47 \pm 2.44$ & 0.959 \\
\hline $\mathrm{HC}(\mathrm{cm})$ & $34.10 \pm 2.74$ & $32.96 \pm 2.34$ & $35.27 \pm 2.64$ & $<0.0001$ \\
\hline WHR & $0.84 \pm 0.11$ & $0.863 \pm 0.14$ & $0.81 \pm 0.04$ & 0.0002 \\
\hline \multicolumn{5}{|l|}{ Physical Activity Level } \\
\hline MET Score(min/week) & $1726 \pm 1831$ & $2274 \pm 1973$ & $1167 \pm 1488$ & $<0.0001$ \\
\hline Sedentary(min/week) & $504.20 \pm 117.40$ & $517.9 \pm 115.60$ & $490.30 \pm 118.20$ & 0.097 \\
\hline
\end{tabular}

Categorical data presented as proportion and compared using chi-square. Continuous data presented as Mean $\pm S D$ and compared using unpaired t-test 
Nutritional status among Senior High Students Dapare et al.,

Table 2: Nutrient Intakes of Study Subjects Stratified by Gender

\begin{tabular}{|c|c|c|c|c|}
\hline Variable & Total $(n=200)$ & Male $(n=101)$ & Female $(n=99)$ & p-value \\
\hline Total calories(kcal/day) & $4177 \pm 7569$ & $5417 \pm 9839$ & $2912 \pm 3787$ & 0.0189 \\
\hline Carbohydrates(g/day) & $628.10 \pm 1279$ & $792.10 \pm 1598$ & $460.90 \pm 811.40$ & 0.0401 \\
\hline Proteins(g/day) & $169.90 \pm 477.80$ & $227.80 \pm 631.40$ & $110.70 \pm 223.20$ & 0.0282 \\
\hline Fats(g/day) & $141.80 \pm 354.70$ & $182.60 \pm 454.30$ & $100.10 \pm 203.60$ & 0.1002 \\
\hline Calcium(mg/day) & $605 \pm 1417$ & $722.80 \pm 1728$ & $484.90 \pm 1000$ & 0.2361 \\
\hline Phosphorus(mg/day) & $1113 \pm 2954$ & $1399 \pm 3755$ & $820.70 \pm 1779$ & 0.1672 \\
\hline $\operatorname{Iron}(\mathrm{mg} /$ day) & $49.11 \pm 155.00$ & $71.95 \pm 214.40$ & $25.80 \pm 28.81$ & 0.035 \\
\hline Vitamin A( $\mu \mathrm{g} /$ day $)$ & $289.60 \pm 1576$ & $410.60 \pm 2204$ & $166.30 \pm 242.70$ & 0.2742 \\
\hline Vitamin $\mathrm{C}(\mu \mathrm{g} /$ day $)$ & $33.42 \pm 168.00$ & $44.83 \pm 231.00$ & $21.77 \pm 50.52$ & 0.333 \\
\hline
\end{tabular}

Continuous data presented as Mean $\pm S D$ and compared using unpaired t-test
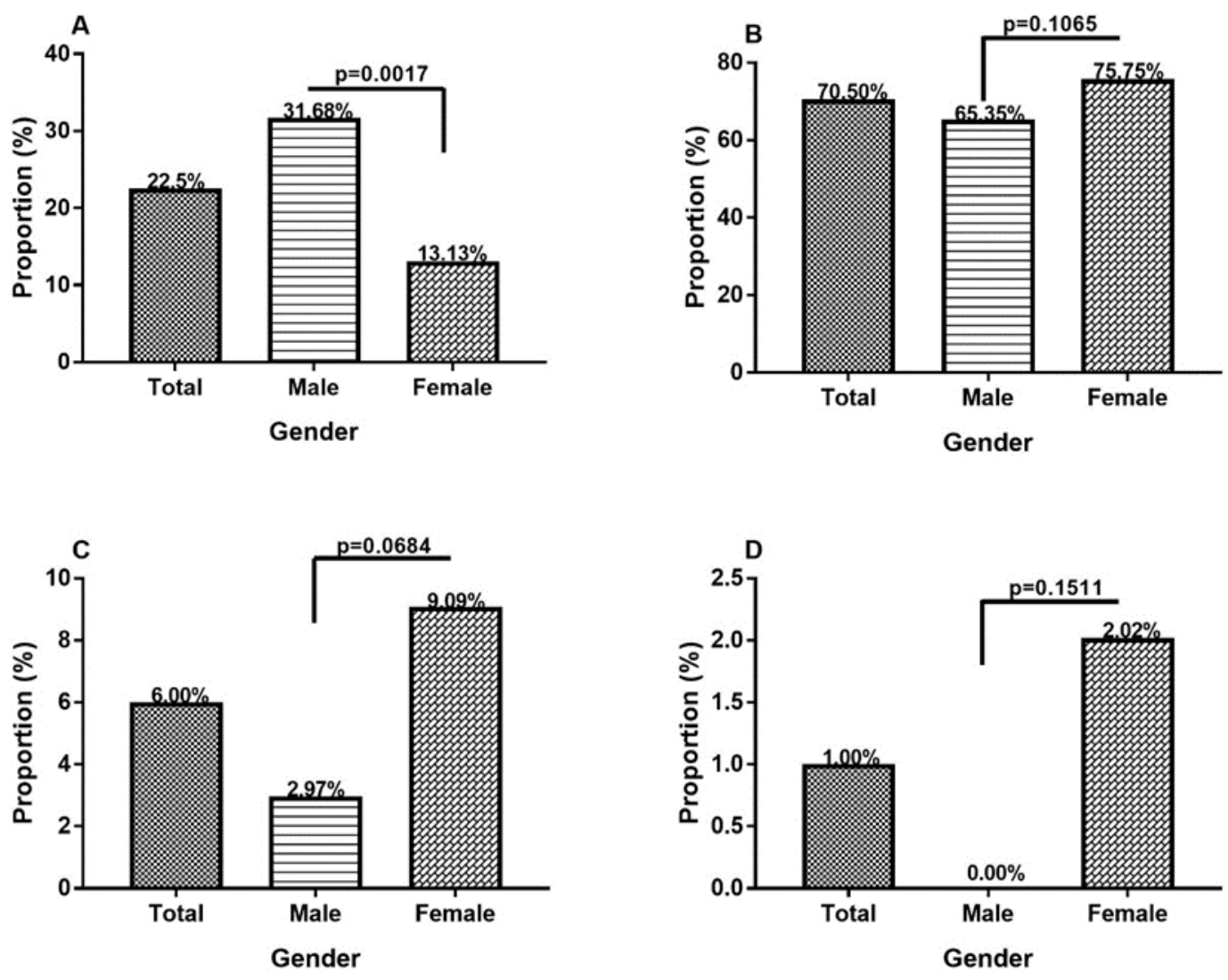

Figure 1: The distribution of underweight (A), normal weight (B), overweight (C) and obese (D) using BMI among the studied participants classified gender

As shown in Figure 2, using Waist-to-Hip ratio as the criteria for classification, $123(61.5 \%)$ were normal weight, $56(28 \%)$ overweight, and $21(10.5 \%)$ obese. There were significantly higher proportions of overweight $(45.45 \% ; \mathrm{p}=<0.0001)$ and obese $(17.17 \% ; \mathrm{p}=0.0023)$ females than males $(10.89 \%$ and $3.96 \%$ respectively), whiles the proportion of normal weight was significantly $(\mathrm{p}<0.0001)$ higher 

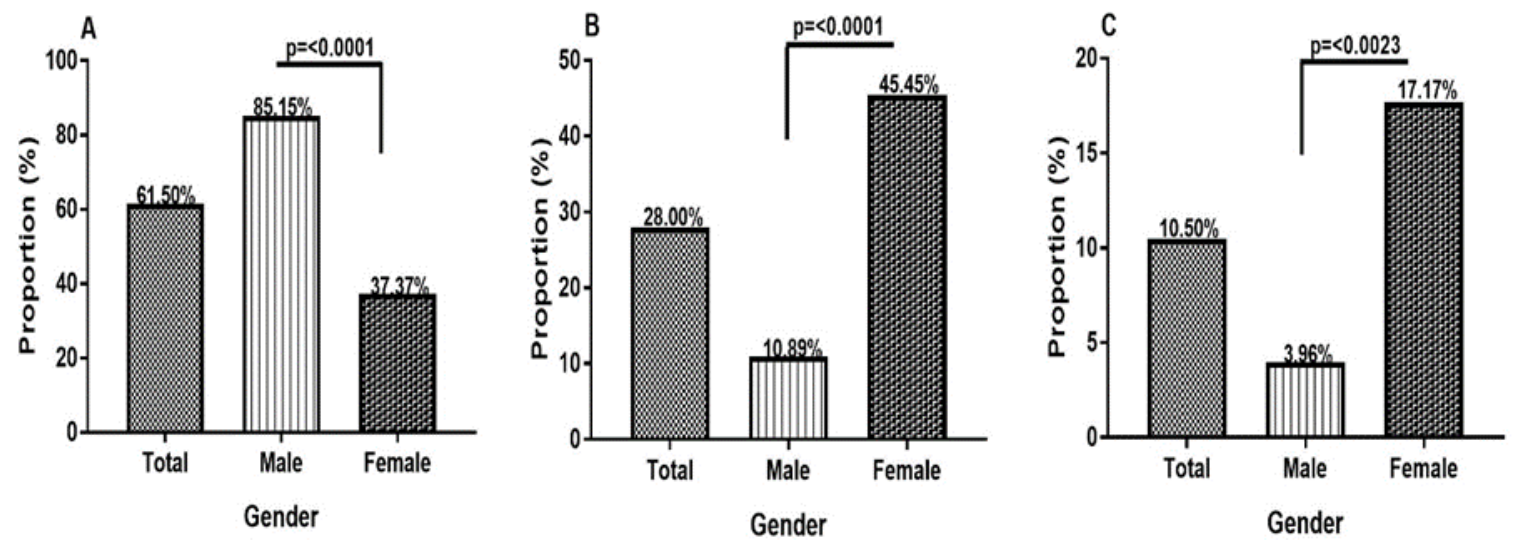

Figure 2: The distribution of normal weight (A), overweight (B) and obese (C) using WHR as an indicator among the studied participants classified by gender
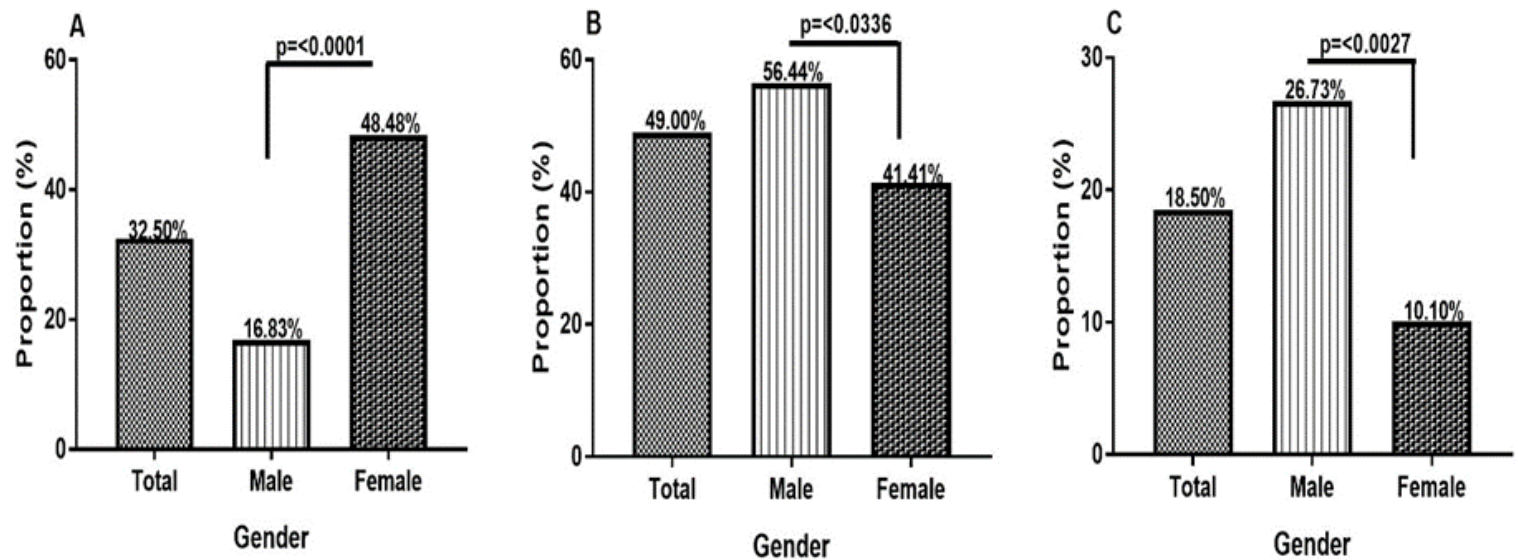

Figure 3: The distribution of Low PA (A), Moderate PA (B) and High PA (C) classified by gender

in males $(85.15 \%)$ than females $(37.37 \%)$.

Furthermore, $65(32.5 \%)$ of the participants engaged in low or no physical activity, $98(49 \%)$ engaged in moderate physical activity, and $37(18.5 \%)$ engaged in high physical activity. More females engaged in low physical activity $(48.48 \% ; \mathrm{p}=<0.0001)$ than males $(16.83 \%)$ whiles more males engaged in moderate and high physical activity levels (56.44\%; $\mathrm{p}=0.0336$ and $26.73 \% ; \mathrm{p}=0.0027$ respectively) than in females (41.41\% and $10.10 \%$ ) (Figure 3).
Anthropometry of Study Population Stratified by School

The mean age of the students in the Boarding school (17.49 $\pm 1.51 ; \mathrm{p}=0.0074)$ was significantly lower than that of the Day students (18.14 \pm 1.86$)$. Participants from the Boarding school were taller $(1.75 \pm 0.08 ; \mathrm{p}=<0.0001)$ than their counterparts from Day school (1.64 \pm 0.08$)$. In comparison, the mean BMI, WC, and MET Score are significantly higher in Day students $(22.03 \pm 2.90 ; \mathrm{p}=<0.0001$, $29.21 \pm 5.85 ; p=0.0278$ and $2221 \pm 1623 ; p=0.0006$ for BMI, WC and MET Score respectively) than 
Nutritional status among Senior High Students Dapare et al.,

Table 3: Demographic and Anthropometric Characteristics of Study Subjects Stratified by School

\begin{tabular}{lccc}
\hline Variable & Boarding $(\mathbf{n}=\mathbf{1 1 2})$ & Day $(\mathbf{n}=\mathbf{8 8})$ & p-value \\
\hline Age(years) & $17.49 \pm 1.51$ & $18.14 \pm 1.86$ & 0.0074 \\
Anthropometry & & & \\
Weight $(\mathrm{kg})$ & $59.18 \pm 7.70$ & $59.56 \pm 9.20$ & 0.7548 \\
Height $(\mathrm{m})$ & $1.75 \pm 0.08$ & $1.64 \pm 0.08$ & $<0.0001$ \\
BMI $\left(\mathrm{kg} / \mathrm{m}^{2}\right)$ & $19.48 \pm 2.59$ & $22.03 \pm 2.91$ & $<0.0001$ \\
WC $(\mathrm{m})$ & $27.87 \pm 2.25$ & $29.21 \pm 5.85$ & 0.0278 \\
HC(m) & $33.87 \pm 2.58$ & $34.39 \pm 2.92$ & 0.1863 \\
WHR & $0.83 \pm 0.06$ & $0.85 \pm 0.14$ & 0.0989 \\
Physical Activity Level & & & \\
MET score(min/week) & $1337 \pm 1898$ & $2221 \pm 1623$ & 0.0006 \\
Sedentary(min/week) & $570.30 \pm 102.20$ & $420.20 \pm 73.89$ & $<0.0001$ \\
\hline
\end{tabular}

Continuous data are presented as Mean $\pm S D$ and compared using unpaired t-test

Table 4: Nutrient Intake of Study Subjects Stratified by School

\begin{tabular}{lccc}
\hline Variable & Boarding $(\mathbf{n}=\mathbf{1 1 2})$ & Day $(\mathbf{n}=\mathbf{8 8})$ & p-value \\
\hline Total calories(kcal/day) & $3695 \pm 8096$ & $4792 \pm 6835$ & 0.3101 \\
Carbohydrates(g/day) & $574.40 \pm 1323$ & $696.50 \pm 1223$ & 0.5043 \\
Proteins(g/day) & $166.70 \pm 591.40$ & $173.90 \pm 275.30$ & 0.9165 \\
Fats(g/day) & $111.30 \pm 283.80$ & $180.50 \pm 427.00$ & 0.1713 \\
Calcium(mg/day) & $461.30 \pm 978.10$ & $788 \pm 1819$ & 0.1057 \\
Phosphorus(mg/day) & $892.10 \pm 2773$ & $1393 \pm 3164$ & 0.2347 \\
Iron(mg/day) & $49.36 \pm 172.70$ & $48.79 \pm 130.10$ & 0.9796 \\
Vitamin A( $\mu \mathrm{g} /$ day) & $177.90 \pm 231.40$ & $431.90 \pm 2362$ & 0.2591 \\
Vitamin $\mathrm{C}(\mu \mathrm{g} /$ day) & $19.61 \pm 39.25$ & $50.98 \pm 249.00$ & 0.1905 \\
\hline
\end{tabular}

Continuous data are presented as Mean $\pm S D$ and compared using unpaired $t$-test

Boarding students (19.48 $\pm 2.59,27.87 \pm 2.25$ and $1337 \pm 1898$ for BMI, WC and MET Score respectively) whiles time spent on Sedentary lifestyle/week was higher in Boarders (570.30 $\pm 102.20 ; \mathrm{p}=<0.0001)$ than Day students $(420.20 \pm 73.89)$ as shown in Table 3.

\section{Nutrient Intake Stratified by School}

Even though the total calorie intake and intake of other nutrients with the exception of Iron was generally higher among students in Day students than in boarding students, these differences were not statically significant (Table 4).

Nutritional Status and Physical Activity Level Stratified by School

When BMI was used as a criterion for weight classes, the proportion of underweight was significantly higher in Boarders $(33.04 \%$; $<0.0001)$ than in Day students $(9.09 \%)$. The proportion of normal weight and overweight were significantly higher in Day students $(79.55 \% ; \mathrm{p}=0.0129$ and $10.23 \% ; \mathrm{p}=0.0257$ respectively) (Figure 4).

As shown in Figure 5 using WHR, despite the distribution of normal weight and overweight being higher among the Boarders and that of obesity being higher among Day students, these differences were not significant.

Low Physical Activity level was more common among students in Boarding school (46.43\%; $\mathrm{p}<0.0001)$ than in Day students whiles the proportion of students who engaged in Moderate and High Physical Activity levels were significantly higher in Day students $(56.82 \% ; \mathrm{p}=0.0499$ and $28.41 \%$; 0.0014 respectively) than in Boarding students $(42.86 \%$ and $10.71 \%$ ) (Figure 6 ). 
Nutritional status among Senior High Students

Dapare et al.,
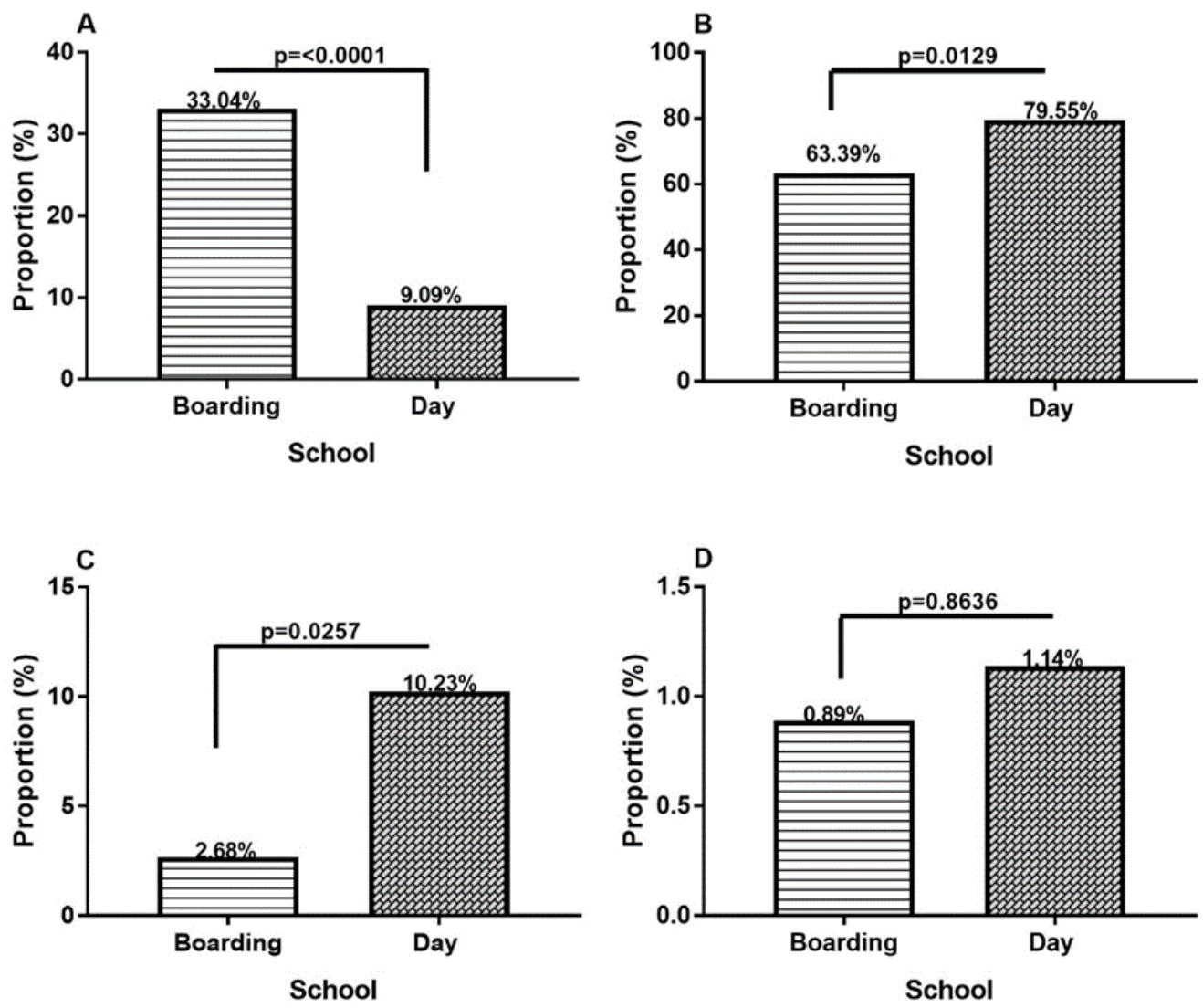

Figure 4: The distribution of underweight (A), normal weight (B), overweight (C) and obese (D) using BMI among the studied participants classified by school
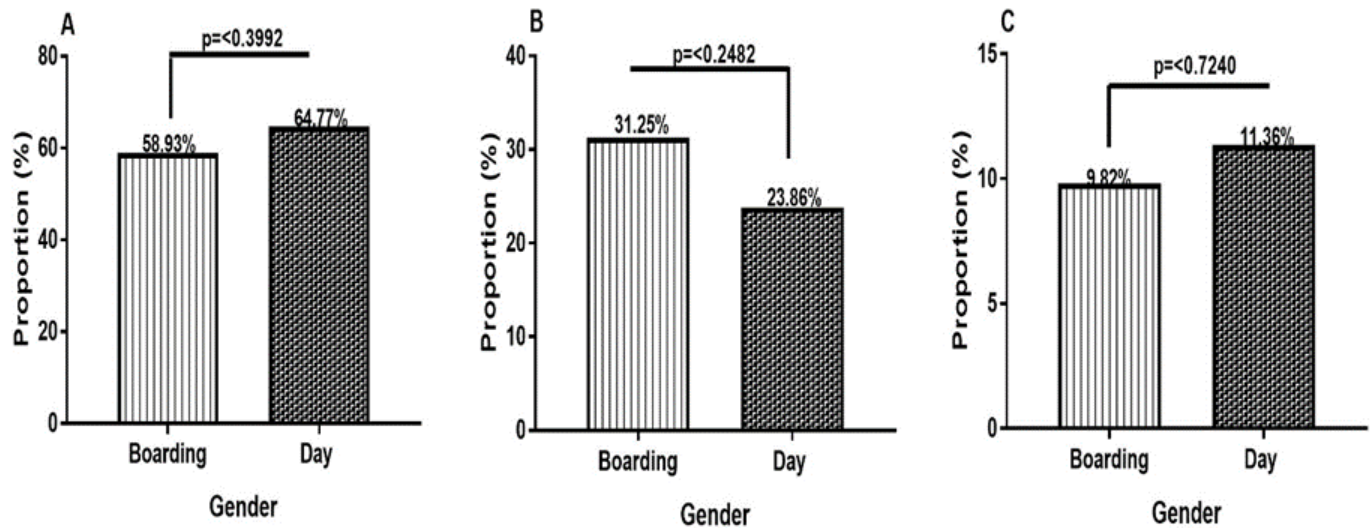

Figure 5: The distribution of normal weight (A), overweight (B) and obese (C) using WHR as an indicator among the studied participants classified by school 
Nutritional status among Senior High Students Dapare et al.,
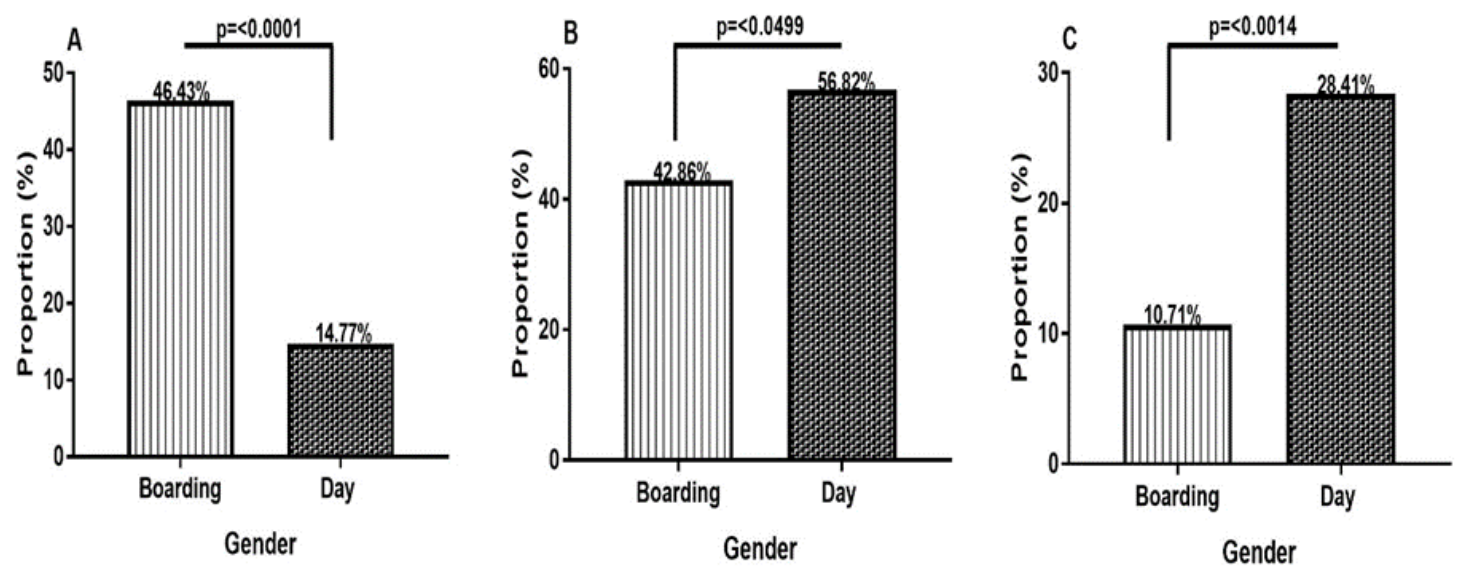

Figure 6: The distribution of Low PA (A), Moderate PA (B) and High PA (C) classified by school Table 5: Energy Intake and Physical Activity Level Stratified by Nutritional Status

\begin{tabular}{lccccc}
\hline Variable & Underweight (n=45) & Normal (n=141) & Overweight (n=12) & Obese (n=2) & p-value \\
\hline RDI & & & & & \\
$<$ RDI & $23(51.11 \%)$ & $59(41.84 \%)$ & $8(66.67 \%)$ & $1(50 \%)$ & 0.9599 \\
Normal RDI & $6(13.33 \%)$ & $27(19.15 \%)$ & $2(16.67 \%)$ & $1(50 \%)$ & 0.2824 \\
$>$ RDI & $16(35.56 \%)$ & $55(39.01 \%)$ & $2(16.67 \%)$ & $0(0 \%)$ & 0.3630 \\
Physical Activity & & & & & \\
Low & $14(31.11 \%)$ & $46(32.62 \%)$ & $4(33.33 \%)$ & $1(50 \%)$ & 0.6964 \\
Moderate & $26(57.78 \%)$ & $64(45.39 \%)$ & $7(58.33 \%)$ & $1(50 \%)$ & 0.4741 \\
High & $5(11.11 \%)$ & $31(21.99 \%)$ & $1(8.33 \%)$ & $0(0 \%)$ & 0.6521 \\
\hline
\end{tabular}

Categorical data are presented as proportion and compared using chi-square for trend

Required Dietary Intake (RDI) and physical activity level stratified by nutritional Status

Among those whose caloric intake was less than the RDI, 23 (51.1\%) were underweight, 59(41.8\%) normal weight, $8(66.7 \%)$ overweight, $1(50.0 \%)$ obese. Out of those whose caloric intake was normal, 6 $(13.33 \%)$ were underweight, $27(19.2 \%)$ normal weight, $2(16.7 \%)$ overweight, $1(50.0 \%)$ obese. Out of those whose caloric intake was $>$ RDI, 16(35.6\%) were underweight, 55(39.0\%) were normal, 2 $(16.7 \%)$ Overweight with none being obese. Generally, there was no observable trend in the proportion of subjects in the various weight classes who were either taking below, above or within the required dietary intake (Table 5).
Out of those with low physical activity level, 14 $(31.1 \%)$ were underweight, $46(32.6 \%)$ normal weight, 4(33.3\%) overweight, and 1(50.0\%) Obese. Out of those with moderate physical activity level, majority $7(58.33 \%)$ were Overweight whiles 26 $(57.78 \%)$ were underweight. Out of those with high physical activity level, $31(21.99 \%)$ were normal weight, $1(8.33 \%)$ were overweight, with none being obese. Generally, the proportion of students who undertook low physical activity increased whiles moving from underweight to obese (Table $5)$.

\section{DISCUSSION}

The issues of nutrition and dietary habits are timely 


\section{Nutritional status among Senior High Students}

Dapare et al.,

because nutrition plays an important part among the external factors that may impact the health of an individual (Deshmukh et al., 2006). Despite the importance of nutrition and dietary issues in adolescents, this has seen little in research. This study aimed at assessing the impact of nutrient intake and physical activity on nutritional status of second cycle students.

The prevalence of overweight and obesity in this study were $28 \%$ and $10.5 \%$ respectively, these findings are consistent with those of Intiful et al. (2013) and Petribú et al. (2011) but higher than those of Kumah et al. (2015), who reported a prevalence of $12 \%$ and $0.8 \%$ for overweight and obesity respectively. A higher prevalence of overweight and obesity in this study may be as a result of rapid urbanization over the period during which the two studies were conducted. Increased prevalence in obesity and overweight is attributable to urbanization with associated acculturation plagued with changes in diet and physical activity (Mbada et al., 2009).

On the other hand, the prevalence of underweight in this study was found to be $22.5 \%$, comparable to that of Essien et al. (2014) in a similar Nigerian population, but higher than that reported by Kumah et al. (2015). A higher prevalence of overweight and obesity on one hand and underweight on another hand supports the reported dual burden of under nutrition and over nutrition in some countries (LobCorzilius, 2007).

In this study, the prevalence of overweight and obesity were higher among females. Similar observations were made by Nyawornota et al. (2013) in their study among a similar population in Accra, Ghana. Higher prevalence of overweight and obesity in females may be as a result of biological changes associated with female growth hormones (estrogen) which spurt during puberty (Wolfe et al., 1997), coupled with other lifestyle changes. Female secondary sexual characteristics during puberty is generally associated with an increased deposition of body fat in the breast, hips, thighs and buttocks (Wheeler, 1991). Also, this study showed a higher proportion of females being involved in low physical activity. A positive balance in dietary intake and energy expenditure through physical activity have been found to be associated with overweight and obesity (Goran, 1995) hence, despite a lower calorie, protein and carbohydrate intake by females, as seen in this study, the observed higher prevalence of overweight and obesity in females may have resulted from a lower physical activity in females leading to a positive balance of nutrient intake and energy utilization. Thus, a higher prevalence of obesity and overweight in females.

This study also revealed a higher prevalence of underweight in males than in females. This finding is similar to that of Essien et al. (2014). In this study, even though males consumed more calories, carbohydrates and proteins, the higher prevalence of underweight could have resulted from a higher negative energy balance resulting from higher physical activity in males and hence the resulting higher underweight.

The observed higher prevalence of overweight and obesity in females than males in this study was however contrary to findings by Dai et al. (2015), who observed a higher prevalence of obesity and overweight in males than in females in their study on the prevalence of obesity among secondary school students in china. The observed difference in the two studies may be as a result of the cultural differences in the two populations. Males in this study population are culturally expected to exhibit strength and hence involved in more physical activity, however, those of the other study population face no such expectations and yet are given preferential dietary treatment as compared to their female counterparts, since Chinese traditionally see males as more important and therefore give them preferential treatment (Dai et al., 2015).

The state of nutrition in school age children has a short-term and long-term impact on cognitive ability, academic performance and productivity in adulthood. This study also sought to reveal the variations in nutritional status of day and boarding students. In this study, higher BMI and a higher prevalence of overweight was found among day students 
Nutritional status among Senior High Students Dapare et al.,

as compared to boarding students. Higher BMI in this study could have resulted from a higher age of day students as compared to boarding students, since generally older adolescents are taller and heavier than younger ones and BMI tends to increase with age among adolescents (Troiano and Flegal, 1998).

The higher prevalence of overweight in the day students from this study which is consistent with Nyawornota et al. (2013) but contrary to Intiful et al. (2013), however could have resulted from proper and/or over nutrition from home and exposure to fast foods and other junk foods since day students are not confined within the walls of the school during off-school hours. Proliferation of fast foods and junk foods have been found to be associated with increased prevalence of overweight and obesity (Mbada et al., 2009).

Boarding students on the other hand are restricted to personal food provisions and the three meals in the school which are sometimes insufficient due to large student populations. A higher prevalence of overweight in day students, despite higher physical activity levels as shown by a higher METscore and a higher proportion of students involved in physical activity could have resulted from a higher intake of junk food during off school hours, leading to a positive energy balance through higher intake of foods as compared to energy expenditure, hence a higher prevalence of overweight.

On the other hand, prevalence of underweight was higher among boarding students, this is consistent with the findings of Luo et al. (2009) who found a higher prevalence of stunting in boarding students than in day students. The findings in the two studies are however contrary to those of Intiful et al. (2013). The higher prevalence of underweight may be as a result of the poor living conditions and nature of meals served in the boarding school.

Similarly, despite the higher sedentary lifestyle among boarding students as shown by higher time spent on sedentary lifestyle and low physical activity and the positive association between increased sedentary lifestyle and higher prevalence of obesity and overweight, students of the boarding school were rather more underweight. This is attributable to poor nutrition leading to a negative energy balance and hence higher prevalence of underweight.

\section{CONCLUSION}

This study highlights the increasing prevalence of underweight, overweight and obesity in adolescents, hence the dual burden of under nutrition and over nutrition. The study also brings to light the higher prevalence of overweight and obesity among female adolescents as a consequence of reduced physical activity. The study also reveals the nutritional deficiencies coupled with reduced physical activity in boarding school students as well as the unhealthy eating habits of day school students. The findings in this study reveals the need for school meals to be planned to be more nutrient-dense and not energy-dense to help reduce the prevalence and incidence of obesity and overweight. Also, activities of boarding schools should be modified to focus on more physical activities, with Female boarding students being encouraged to involve themselves in physical activities to help reduce the prevalence of overweight and obesity. The study also highlights the need for proper education on good dietary and nutritional habits particularly among students of day schools.

\section{COMPETING INTERESTS}

The authors declare that they have no competing interests.

\section{REFERENCES}

Dai N., Tian L., Tao T., Tang T., Sheng Y., Lu X.Q., Tang X., Peng B., Lu W. and Jin Y. (2015) Prevalence of obesity among secondary school students from 2009 to 2014 in China: A Meta-analysis. Nutrición hospitalaria: Organo oficial de la Sociedad española de nutrición parenteral y enteral 31(3), 1094-1101.

Daniels S.R., Arnett D.K., Eckel R.H., Gidding S.S., Hayman L.L., Kumanyika S., Robinson T.N., Scott B.J., Jeor S.S. and Williams C.L. (2005) Overweight in children and adolescents. Circulation 111(15), 1999-2012. 


\section{Nutritional status among Senior High Students}

Dapare et al.,

Deckelbaum R.J. and Williams C.L. (2001) Childhood obesity: the health issue. Obesity research 9(S11), 239S-243S.

Deshmukh P., Gupta S., Bharambe M., Dongre A., Maliye C., Kaur S. and Garg B. (2006) Nutritional status of adolescents in rural Wardha. Indian Journal of Pediatrics 73(2), 139141.

Essien E., Emebu P., Iseh K. and Haruna M. (2014) Assessment of nutritional status and knowledge of students from selected secondary schools in Sokoto metropolis, Sokoto State, Nigeria. African Journal of Food, Agriculture, Nutrition and Development 14(6), 22542268.

Fakhouri T., Hughes J.P., Burt V.L., Song M., Fulton J.E. and Ogden C.L. (2014) Physical activity in US youth aged 12-15 years, 2012. NCHS data brief(141), 1-8.

Gan W., Nasir M.M., Zalilah M. and Hazizi A. (2011) Disordered eating behaviors, depression, anxiety and stress among Malaysian university students. College Student Journal 45 (2), 296-310.

Goran M.I. (1995) Variation in total energy expenditure in humans. Obesity 3(S1), 59-66.

Guo S.S., Wu W., Chumlea W.C. and Roche A.F. (2002) Predicting overweight and obesity in adulthood from body mass index values in childhood and adolescence. The American journal of clinical nutrition 76(3), 653-658.

Intiful F.D., Ogyiri L., Asante M., Mensah A., SteeleDadzie R. and Boateng L. (2013) Nutritional status of boarding and non-boarding children in selected schools in the Accra metropolis. Journal of Biology, Agriculture and Healthcare 3(7), 156-162.

Kumah D., Akuffo K., Abaka-Cann J., Affram D. and Osae E. (2015) Prevalence of overweight and obesity among students in the Kumasi metropolis. Journal of nutrition and metabolism 2015.

Lob-Corzilius T. (2007) Overweight and obesity in childhood-A special challenge for public health. International journal of bygiene and environmental bealth 210(5), 585-589.
Luo R., Shi Y., Zhang L., Liu C., Rozelle S. and Sharbono B. (2009) Malnutrition in China's rural boarding schools: The case of primary schools in Shaanxi Province. Asia Pacific Journal of Education 29(4), 481-501.

Mbada C.E., Adedoyin R.A. and Ayanniyi O. (2009) Socioeconomic status and obesity among semi-urban Nigerians. Obesity facts 2(6), 356 $-361$.

Nyawornota V., Aryeetey R., Bosomprah S. and Aikins M. (2013) An exploratory study of physical activity and over-weight in two senior high schools in the Accra Metropolis. Ghana medical journal 47(4), 197.

Petribú M.d.M.V., Tassitano R.M., Nascimento W.M.F.d., Santos E.M.C. and Cabral P.C. (2011) Factors associated with overweight and obesity among public high school students of the city of Caruaru, Northeast Brazil. Revista Paulista de Pediatria 29(4), 536545.

Popkin B.M. (2002) An overview on the nutrition transition and its health implications: the Bellagio meeting. Public health nutrition 5 (1A), 93.

Popkin B.M., Horton S., Kim S., Mahal A. and Shuigao J. (2001) Trends in diet, nutritional status, and diet-related noncommunicable diseases in China and India: the economic costs of the nutrition transition. Nutrition reviews 59(12), 379-390.

Sharma S.V., Gernand A.D. and Day R.S. (2008) Nutrition knowledge predicts eating behavior of all food groups except fruits and vegetables among adults in the Paso del Norte region: Qué Sabrosa Vida. Journal of nutrition education and behavior 40(6), 361-368.

Troiano R.P. and Flegal K.M. (1998) Overweight children and adolescents: description, epidemiology, and demographics. Pediatrics 101(Supplement 2), 497-504.

Wheeler M.D. (1991) Physical changes of puberty. Endocrinology and metabolism clinics of North America 20(1), 1-14.

WHO (1995) The use and interpretation of anthropometry. Geneva CH: WHO 1995, technical report 854. 
Nutritional status among Senior High Students Dapare et al.,

WHO (2000) Management of the child with a serious infection or severe malnutrition: guidelines for care at the first-referral level in developing countries: World Health Organization.

WHO (2006a) Food and nutrition policy for schools: a tool for the development of school nutrition programmes in the European Region.

WHO (2006b) Global strategy on diet, physical activity and health: a framework to monitor and evaluate implementation.
Wolfe W., Sobal J., Olson C., Frongillo Jr E. and Williamson D. (1997) Parity-associated weight gain and its modification by sociodemographic and behavioral factors: a prospective analysis in US women. International Journal of Obesity \& Related Metabolic Disorders 21(9).

Woodruff B.A. and Duffield A. (2000) Adolescents. Assessment of nutritional status in emergency-affected populations.
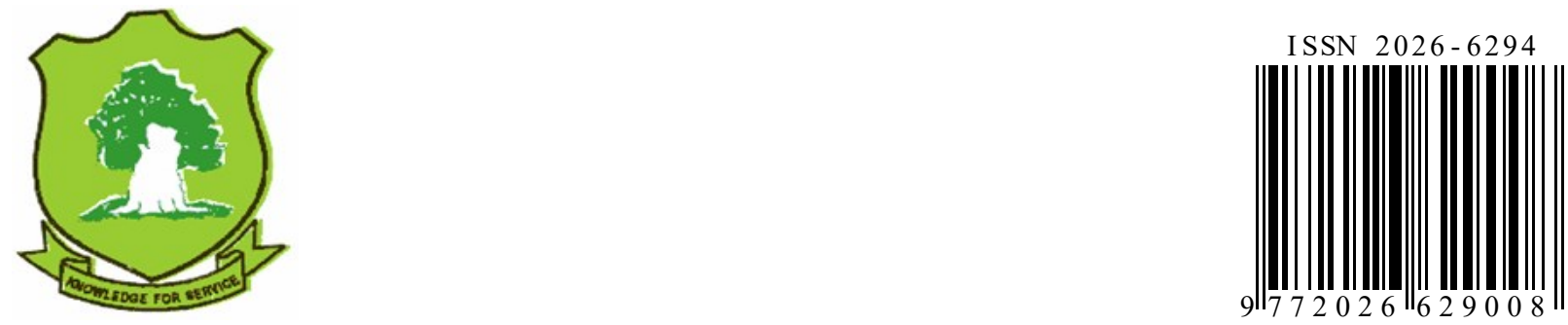